\title{
COMPARING SUSTAINABILITY OF NEW EGYPTIAN SETTLEMENTS VERSUS TRADITIONAL EGYPTIAN CITIES: A COMPARISON OF MASR EL-GDIDA AND NEW CAIRO CITY.
}

\author{
Islam Ghonimi Ibrahim and Hassan Ahmed El Zamly \\ Shoubra Faculty of Engineering
}

\begin{abstract}
The debate of changing development patterns from the traditional in old Egyptian cities to modern neighborhood in new Egyptian settlements still constitutes a controversial matter for different interest groups. Residents, planners, and authority thought that this change could be a solution for old town's problems, where residents can find calm, safety and open greenery spaces high parking area, and low traffic cognition. On the other hand, different scholars have increasingly emphasized that traditional compact, mixed use, high-density urban forms is important for reaching sustainability goals in term of environmental, economic and social advantages. Based on comparison of traditional and new settlements in Egypt; this research examine the sustainability of New Egyptian Settlements. This research argues that moving from traditional to modern neighborhood rather than be the solution for development of Traditional Egyptian Cities, it becomes part of problem of development of modern Egyptian settlement. The purpose of this research is to examine the contribution of moving from traditional to modern urban form with reference to GCR new towns.
\end{abstract}

Keywords: Traditional cities versus New Settlements, GCR, Development Evaluation Indicators, sustainable urban form.

\section{INTRODUCTION:}

Greater Cairo Region is different from any other region in term of social, economic and environmental circumstances. It requires an urban pattern that fit to these unique characteristics in order to achieve urban development. The right choice of development pattern is important to positively affect communities' development. Accordingly, all decision makers and planners propose different development patterns in an attempt to satisfy the required development within an appropriate urban context. Egyptian authorities adopted modern neighborhood as new development patterns with its hope to achieve urban development, and to introduce better solution to solve the problem of GCR new towns. Planners and authority thought that changing urban form from traditional urban form to modern neighborhood could be a solution for modern cities problems, like safety, sense of community and other. Unfortunately, their socio-spatial characteristics cause a number of development problems and negative impacts on the social and spatial fabric of new Egyptian cities. This research aims to examine the contribution of both traditional and modern patterns to urban development with especial reference to GCR's Egyptian cities and settlements.

\subsection{Research Problem:}

The second half of the twentieth century, Egyptian context of modernization turns the concepts of development and its patterns to western modernization. In this period, Egypt has witnessed the establishment of many new residential districts that obeyed western modernization concepts. As the current settlement strategy in Egypt is relatively new and borrowed from the UK (Shalaby 2003), neighborhood patterns have turned from globalized westernized world into Egyptian context. Almost all the plans of the new cities based on the modern theories of residential district with segregating land uses pattern, of pure residential clusters, with services concentrated in centers (Asmaa Ibrahim, 2007).

The state started to transplant neighborhood models within unique context like Egypt, without making the proper attempt to test their compatibility for development in Egypt. These patterns 
borrowed from environments that are not similar to local circumstances, and could neglect local context requirements, and may not be suitable for application in local circumstances. That is why they need to undergo the revisionist criticism. The criticism must meet the antithesis to explore issues that are not clear, hence, the revisionist criticism needs to meet theories of sustainable urban development in local circumstances.

\subsection{Research Aim:}

Some development patterns could enhance urban sustainability, whereas others do not. An understanding of the reason that some neighborhoods provide more sustainable development than others is important to improve urban development. The study concerns to explore a comparison of sustainability between old cities and new Egyptian settlements, based on a comparison of two cases of Masr El-Gdida and New Cairo City.

\subsection{Research Hypothis:}

The research argues that changing urban form from traditional to modern urban form in new Egyptian cities rather than be the solution for traditional cities problems of development, it becomes part of new settlements problem of development established in GCR. It would make them less sustainable in terms of environmental, social and economic aspects. which necessitate revisionist research effort to correct these trends.

\subsection{Research Method:}

In order to test this hypo this, the research depends on a deductive method with comparative analysis, to establish a sense of anti-thesis criticism of these unique features and conditions which involves three parts:

The first part: Theoretically, discusses and theories of sustainable urban development and deduces shared development indicators and their prerequisite successful socio-spatial configuration.

The second part: introduces a comparative analysis to deduce the main of socio-spatial differences between modern and traditional micro urban form, in micro and macro scale.

The third part: critically project the deduced shared development indicators to both traditional and new settlement in order to analyze and assess their contribution to urban development.

\section{SUSTAINABLITY OF URBAN FORM (Theoritical Reveiw)}

Sustainabile urban development referes to the development that satisfies current needs of cities without compromising the ability of future generations to meet their own needs. In addition, it is an idea moved beyond the focus on ecology and the natural environment to include social, economic and institutional dimensions. Different classical and modern theories described, from their own point of view, the ideal performance of a city that make it positively achieve sustainability issues. They put forward their points of view regarding how the city should function, what it should provide for its residents and what the relationship should be with the natural environment to achieve sustainability goals. They thought that certain urban form patterns could perform best to achieve sustainability of development than others. They suggest a successful socio-spatial fabric for the city.

\subsection{CLASSICAL THORIES:}

Starting from "The Fractal City" of Salingarous (Salingaros 2004) that contains high degree of urban life, that directly depends upon a matrix of connections and substructure at all scales in a hierarchy, from the very large to the very small, encourages people's movements, interactions and connection. In addition, Peter Calthorbe (Calthorpe 2004) who developed the concept of transit-oriented development, considering the corridors as the most important element that is connector of neighborhoods and districts. He argued that Human-made corridors are important to the quality of life within a region road. Low (Low 1996) conceptualized various types of cities among them, the divided city and the fortress city. She argued for the divided city that evoked due to hidden barriers of race and class, unequal distribution of culture capital and social capital. In addition, the fortress city; that evoked due to implicitly explicitly using barriers, through the privatization of certain spaces for the purpose of certain groups excluding unwanted. 
Christopher Alexander (Alexander 1961) argued that there are different ways of collecting a large collection of small systems like cities parts, among them the tree model and the lattice model, both of them structure of a sets. When these small parts interact with each other and make co-operate by inner binding force that called a system. When the structure is a system called a semi-lattice, rather it is a tree.

He argued that a living city is modeled by a mathematical semi lattice, in contrast to a dead city, which is modeled by a tree. A semi lattice has a vastly larger number of internal connections that should have a great variety. To be livable, we must return to traditional and natural states of place-creation, a place must generate a sense of belonging in its users, participatory, self-created. He argued that dissatisfaction with the modern city stems from their artificial organization into hierarchical groupings of facilities, which he suggests, based not on the way people use the city, but on the way designers conceive the process of design and apply it to the design of a city.

John Minette (Minette 1975) argued that all activity systems are linked to each other; these links provide the framework of constraints and potentialities with in which agency work so the design for these links is the planner field. He argued that planners should concern with the positive design of public areas and resources as overlapped with public-private systems and linked to activity systems. Jan Jacobs (Jacob 1961) argued that neighborhoods to work best should not have beginnings or ends it need to overlap and interweave with their surroundings. She questioned the use of boarders, criticizing that not boarders that made neighborhood but the activities going on in the streets. Boarders often creates barriers and defeated the cross uses occurring between the neighborhoods.

Engwicht (Engwicht n.d.) argued that the main function of cities, to maximize the opportunities for exchange, therefore he found the role of physical form of the city is to assure the relation between city parts and its impact on residents life and social connection. He argued against the auto-dependent behavior that could reduce transportation, which could reduce opportunities for exchange. He argue that with growing distance between city parts and urban and social fabric exchange, public transportation become less feasible and reduce the opportunities for exchange, especially for elder, poor, and children. He argues for the importance of public spaces as a place connecting different social groups together. He suggested that Complexity and diversity are important for city life, it offers the chance for different elements to meet, interact and exchange, which are impossible in a totally ordered world. In addition, the transportation network and depending on a private car could eliminate these Complexity and diversity.

\subsection{SUSTAINABLE DEVELOPMENT MOVEMENT:}

Sustainable urban development movement concerns the long-term prospect for future existence of urban development to meet the needs of the present without compromising the ability of future generations to meet their own needs", (United Nations. 1987, UN Habitat 1996, Sustainable Cities Programmed). The UN Habitat's Program for Sustainable Cities, define a sustainable city as a city where achievements in social, economic and physical development made to last:

Environmental sustainability: An environmentally sustainable city designed with consideration of environmental impact, to reduce the overall impact of the built environment on human health and the natural environment. First: In term efficiency in using energy, water, and other resources minimization of required inputs of energy, water. Second: in term of protecting occupant health and improving employee productivity. Third: in term of Reducing waste, pollution and environmental degradation waste output of heat, air pollution - $\mathrm{CO} 2$, methane, and water pollution.

Social sustainability: A socially sustainable system must achieve social equity in the distribution of development benefits and costs. Social sustainable urban form refers to the ability of a city to sustain orderly relationship among its diversified residents and for them to meet their hierarchy of needs (Pongsmas, n 2004). First: It depends on economic efficiency in the use of resources provided by natural resources. Second: It depends on economic growth with ensuring social equity, to be equitable for equitable distribution of land uses and housing 
types. Third: It depends on enhance public realm to support opportunities for economic exchange.

Economic sustainability: An economic sustainable system must achieve efficiency in using development resources. First: in term of equity, that refers to the fair distribution and access to resources among individuals and groups; to facilitate full participation and collaboration, in their community and have opportunities for personal development and advancement. Second: In term of social inclusion and interaction, refer to both the right and the opportunity to participate and enjoy all aspects of community life and interact with other community members; where the environment enables individuals to celebrate their diversity and react and act on their responsibilities. Fourth: Adoptability and resilience, refers to the individual groups ability to respond appropriately to change.

\subsection{NEW URBANISM:}

New urbanism is a movement started by the leaders who created the congress of new urbanism in Sanfrancisco early 1990s, are Anders Duany, Elizabeth Plater-zyberk, Peter Calthorpe, and Elizabeth Moule. Traditional neighborhood (TND) of Elizabeth PlaterZyberk, and transit oriented development (TOD) of Peter Calthorpe (Calthorpe 2004), and smart growth (Smart Growth Network, 2000), and urban village. They finalized a charter of new urbanism comprises a list of 27 principles, each of which is accompanied by an essay from a leading architect, planner, or policy maker that explains it in detail. All such new urbanism movements strive for the same principles of place-making, traditional urban fabricmaking, perspective design regulation, and imagery from idyllic small-town life, low-density development, built on green field sites as speculative new towns, and as corrections to sprawling suburbia.

New Urbanism strives to build communities that are more cohesive, public, interconnected, promote mixed-use developments with a range of housing types, has a network of mass transportation and pedestrian-friendly designs, attempt to build a sense of community via integrating private residential space with surrounding public space, and through careful design and placement of public space (Talen, 1999). New urbanism steer for micro and macro sense of community, which improved by encouraging better relation and connectivity to neighbor and greater region, via promoting a better transportation, bicycle, and pedestrian paths access.

\subsection{LIVABILITY THEORY:}

International making cities livable (IMCL) conference, American Institute of architecture (AIA) and Agenda of Urban task force (1999:19) all discussed the ideas of livable places, they developed general design principles for creating livable communities, to enhance the well-being of inhabitants of cities and towns, strengthen community, improve social and physical health, and increase civic engagement. This explained as follow:

First: A well-functioning public realm - meetings, encounters, dialogue among people young and old with a diversity of backgrounds, acquaintances, friends and strangers - that exists in multi-functional public places, squares and marketplaces. Second: Well programmed public spaces, special events, festivals and urban markets; the valorization of the traditional mixeduse "shop-house" as the basic cellular unit in constructing walk-able urban fabrics, the presence of essential shops and services necessary for functioning of the daily life, and the creation of a "fine-mesh transportation network to reconnect the city and periphery (lennard 1995). Third: The need for public transit, bicycle lanes, and traffic calmed streets, for human scale architecture and mixed use urban fabric, for reviving the city center and creating public places where people could gather for farmers markets, festivals, outdoor cafes and community social life. Fourth: They found livability in the city as a holistic social entity, which requires a network of physical meeting groups to encourage people to communicate, learn from each other, and enjoy the public life.

\subsection{LEED FOR NEIGHBOURHOOD DEVELOPMENT:}

(Leed-ND) leadership in energy and environmental design for neighborhood development is a program administered by the U.S. Green Building Council to improve community and neighborhoods. They developed criteria in term of smart location, neighbourhood pattern and green infrastructure and buildings (USGBC, ). This explained as follow:

First: The smart location aims to define where to build and how to integrate with existing context. It emphasis the fesability of location to design with nature. In the other hand to 
design connected neighbourhood for pedestrians, cyclists, and vehicles with surrounding area to achieve high connectivity to the surrounding area and to avoid barriers such as cul-de-sacs or difficult-to-cross streets- to adjacent areas and uses. Furthermore, it aims to design for public transit that willing to achieve "transit oriented development," that increases the likelihood that people will depend on walking, cycling, and most forms of public transit rather than drive which reduces polution.

Second: Neighbourhood pattern and design, what to build enhance land effeceincy, achieve diverse and convenent neighbourhood, walkable streets, reduced parking and transportation demand, enhance bycicle frindly design, and mix community space. Finally: How to manage the impact on the environment through enhanceing green infrastructure and buildings, reusing older buildings, reducing polution, keeping things cool, neighbourhood wide energy effeceincy, and reuse and recycle.

\subsection{SHARED PREMISES:}

After the intensive review of classical and modern movements that described, from their own point of view, the ideal performance of a city, i.e. how the city should function, what it should provide for its citizens and what the relationship should be with the natural environment. This part intends to use the deduced shared premises and development criteria to assess both traditional and modern Egyptian settlements to urban development.

1. Integration between micro community and macro community.

2. Movement behavior: (walkability and alternative transportation options).

3. Connectivity and Permeability.

4. Encourage public realm to stimulate face-to-face interaction.

5. Encourage safety and security.

6. Encourage diverse and mixed communities.

7. Social appropriateness.

8. Efficient use of resources.

9. Equitable management of resources.

10. Consideration to environmental impact. 11.

\section{THE CASE STUDY OF MASR EL-GDEDA AND NEW CAIRO CITY}

Cairo is exposed to different dramatic shifts in adopted development patterns. Starting from traditional on in old cities, followed by modern one, new egyptian settelments. The case study of traditional and modern cities in Cairo will be investigated. Figure (1) includes a representation of two types of settlements in Greater Cairo Region. It explores the traditional central one and the flourish of new settlements in Greater Cairo region to the west and the east.

New Settlement:

1- Six October

2- El Sheikh Zaid

3- El Obour

4- El Shourouk

5- New Cairo

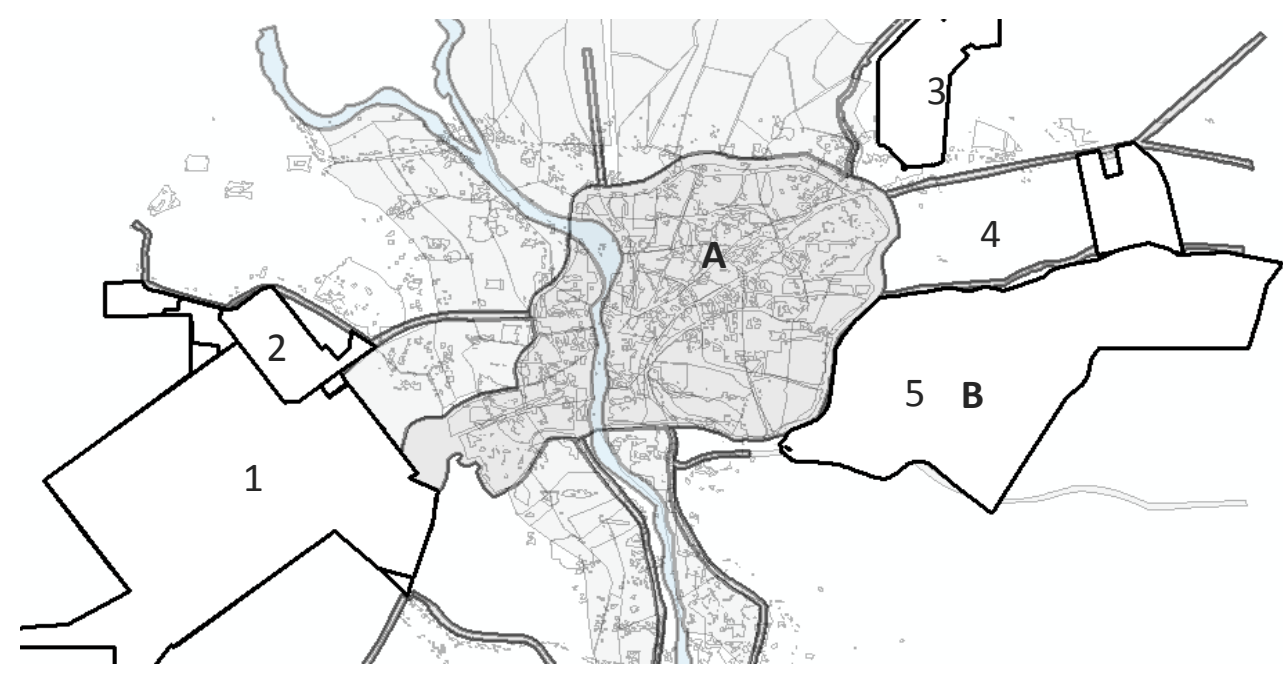

a) New Cairo (new settlement)

b) Masr El-Gdida (old city)

Figure (1): Traditional city and flourish of New Settlements in GCR, selection of case studies. 


\subsection{CASE STUDY SELECTION}

Two case studies are selected to present traditional and new settlements in Egypt. Misr ElGdida is selected to present traditional cities and New Cairo city is selected to present new settlement waves; as it is considered as a spatial extension of Masr El-Gedida to the east. The socio-spatial form of both Masr El-Gdida and New Cairo is analyzed on micro and macro scale and their analysis and socio-spatial measures are presented in Table (1).

\subsection{TRACING DIFFERENCE IN URBAN FORM}

This section explores the socio-spatial difference between traditional and modern settlement in Egypt. In addition, it defines the way in which neighborhood socio-spatial features are collectively affect socio-spatial change and continuity of settlements, to examine their impact on urban development.

\subsubsection{MASR EL-GDEDA AS TRADITIONAL URBAN FORM:}

Masr El Gdeda is one of the developed settlements at the first decade of the twenties century. Paron Imban initiated it in the east desert based on the concept of European middle age cities. It was borrowed from Paris style that obeyed socio-spatial form of new European planning. Its original plan developed based on garden city model. Gradually, at the mid-decade of the twenties century, the gradual development of the city make it turn into a traditional pattern. Due to high land value, the gradual growth neglected the garden city concept and followed the traditional socio-spatial patterns in all its growth, extension and infilling with traditional methods as follow:

In micro scale, Masr El-Gdida depends on radial grid outward oriented street network, small lots, with high fine-grained fabric, no barriers, that are highly connected to each other and enable continuous outward oriented growth to enable the connection with the city as an integrative organic part of the city. It explores relative diversity and mix of housing types, and relative high density with relative high community size. It depends on diverse mixed land use with high quantity of connecting lines between residential and other commercial uses that reflects expanded transit commercial axis, which combines different vertical mixed uses, residential with commercial in ground floor.

In macro scale, Masr El-Gdida is developed with integrated organic parts of a city that has blurring boundaries with fine-grained free large number of entrances accordingly it makes continuous fabric overlapping and interweaving. It creates connected fractal city with pedestrian transportation web that built over time - with continuous incremental additions. It is inclusionary of others and oriented toward the public domain and human dimension. It implies heterogeneity and ample multi-family residential uses. Theoretically, it may be called fractal, connected, and regional city model with a series of interlinked compact nodes or neighborhoods.

\subsubsection{NEW CAIRO CITY AS MODERN URNAM FORM:}

New Cairo City as modern neighborhood developed to reject traditional solutions and started to base on Industrialism, societal community, new science, new technology, modern philosophy of thinking, and development in the sciences of traffics. Neighborhood turned from globalized world into Egyptian context, as the current settlement strategy in Egypt is relatively new and borrowed from the UK (Shalaby 2003). Almost all the plans of the new cities based on the modern theories of master plans of residential district with segregating land uses pattern, of pure residential clusters, with all their services concentrated in centers (Asmaa Ibrahim, 2007 :44). New Cairo city is one of the developed new settlements at the last two decades of the twenties century. It obeyed socio-spatial form of modern neighborhood as follow:

In Micro Scale, New Cairo City depends on treed inward oriented street network using loops and cul-de-sac and has partially and implicitly barriers that restrict the connection with the external community that creates cellular cell isolated and separated from the city. The arterial streets acted like buffers to keep out the unwanted through traffic. In addition, urban form based on few superblocks and superhighways, a process that severely reduces the number of available paths. It breaks large residential developments into relatively large lots of a uniform size and shape inward looking units, with some cul-de-sacs, curvilinear streets, and large homes. It depends on relative homogeneity of housing type; it seems to be designed for young families. It depends on low densities single housing type predominant detached single-family 
homes. It depends on single land-use mostly residential with absence of non-residential land uses and transit services. It aims to separate services area from residential one; hence, the community contains only houses.

In macro Scale, New Cairo City is semi internally focused, separated cellular cell, semi defined boundaries with arterial streets. It is based on super block that is implicitly controlled with low number of entrances. Arterial roads become boarders, which cannot turn into a pedestrian, that cause disengagement from the rest of the region. It is exclusionary of other and relies on homogeneity. They are inward oriented, they usually try to isolate them self out from their broader city context, so they reinforce spatial isolation with land use orientation and street network as a common inward oriented street network pattern. They reduce their relation, connectivity, continuity and interaction with their city fabric, and increase isolation from everything else, (Ghonimi, 2010). It creates inaccissible bockets or islands inside urban fabric, that cut the continuity of urban fabric. By closing off a large number of neighborhoods, the existing road network and spatial structure of city are severely affected and transformed form public road network to a structure of super-block. Large areas are changed from traditional fine-grained urban form into isolated and inaccessible super-blocks that destructs the continuity and connectivity of urban fabric.

Based on the difference between traditional settlements and modern settlements in Cairo, this part intends to criticize both of them resting on modern movements of sustainable urban development in reference to local context in term of environmental, social, and economic characteristics. This part distingue the gap exists between such theories and the practice of modern neighborhood in new Egyptian settlements.

\begin{tabular}{cl}
$\begin{array}{l}\text { Modern Neighbourhood } \\
1^{\text {st }} \text { district, New Cairo City }\end{array}$ & $\begin{array}{l}\text { Traditional Neighbourhood } \\
\text { Medan El Gama - Masr El Gdidar }\end{array}$ \\
\hline
\end{tabular}

Main characteristics Micro Scale

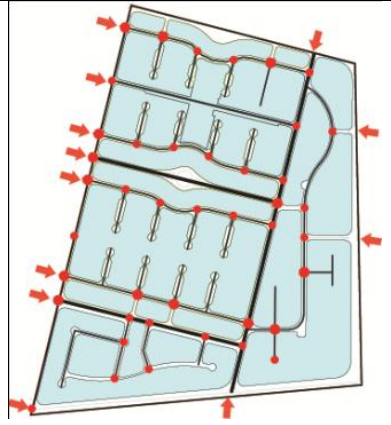

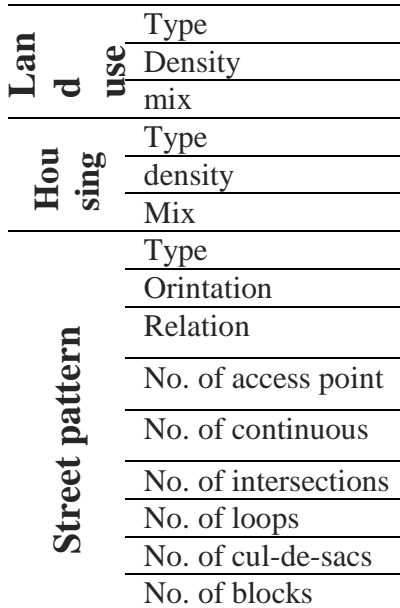

Single land use type(mostly residential) Low denisty No variation so no mixing

Single housing pattern (mostly high) Low denisty No variation \& no mixing Treed (cul-de-sac) Inward orinted Contrast with surrounding 3 3 16 6 16 7

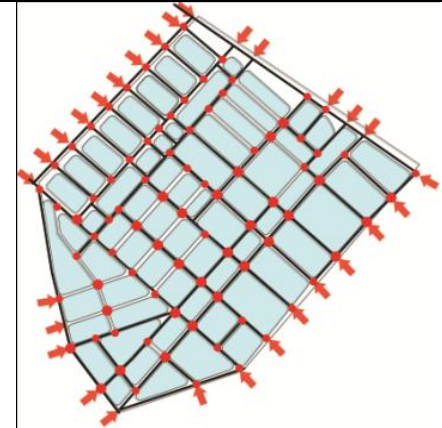

Varied land use type(resid, comm..) High density Mixed uses

Varied housing patterns (high to low) High density Mixed housing type Outward orinted Continuity with surrounding
16
14
55
0
0
63

Table (1): Comparing urban form of traditional versus new settlements (micro scale). 


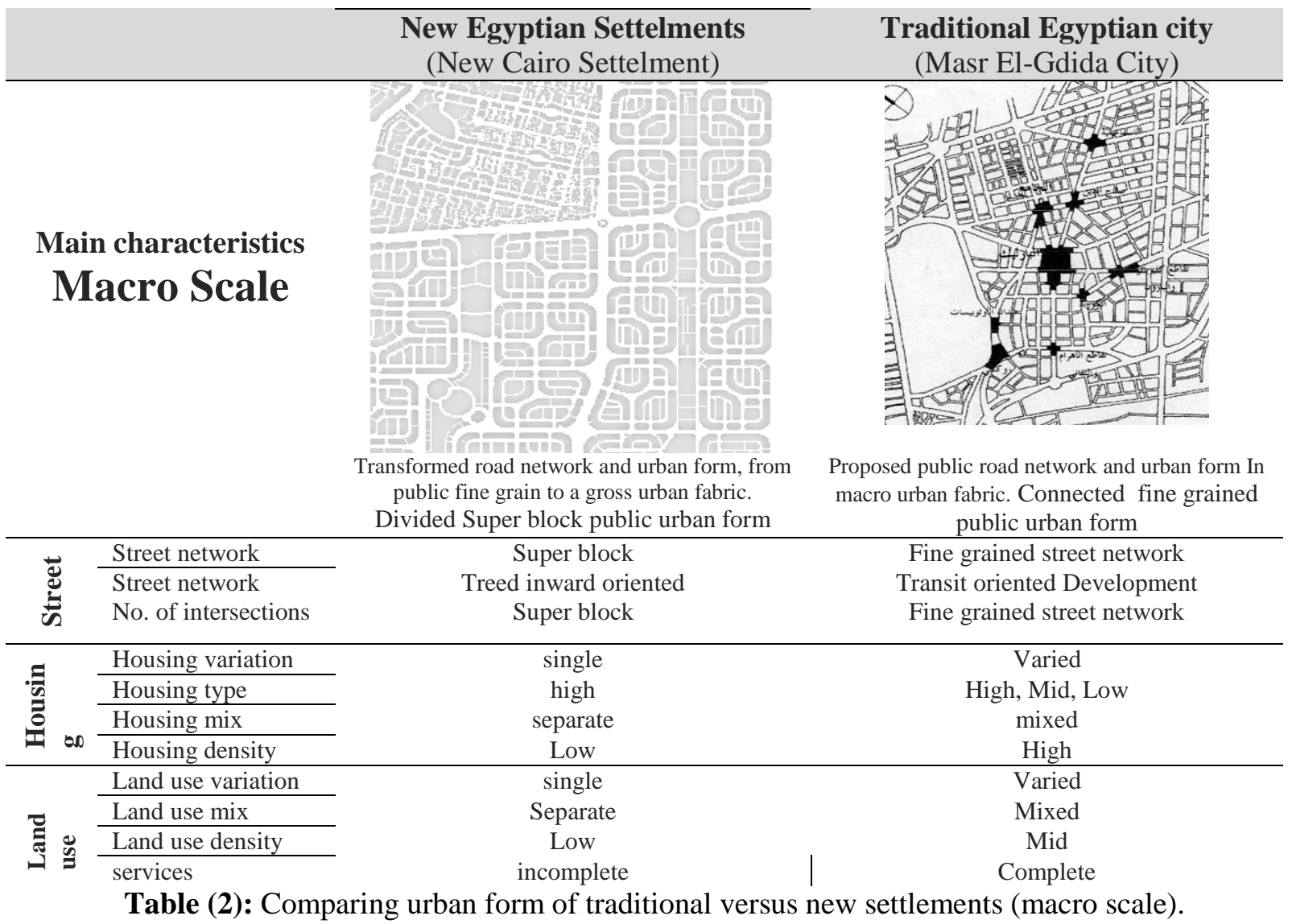

\section{SUSTAINABILITY OF TRADITIONAL VERSUS MODERN ETTLEMENTS:}

To determine the sustainability and appropriateness of new development patterns in Egypt, a criticism in the ground of general review of the economic, social and environmental aspects. This part concerns to apply the deduced shared development criteria to both cases (Masr El Gdida) as a traditional city and (New Cairo city) as modern settlement, in order to theoretically deduce their role in achieving sustainability in unique context like Egypt:

\subsection{Successful Spatial Fabric (micro to macro relationship).}

It considers the scope of successful spatial fabric, that encourge the integration, the interaction and the relation between city parts; to make the city as integrated organism, not standalone entities. It stressed the importance of being part of a city to enhance urban development through haveing blurring boundaries (Jacobs, 1961). Its boarders as primary public spaces between neighborhoods (Jacobs, 1961). It depends on linked structures from the very large to the very small, multilayered transportation network, sufficient fine grained infrastructure to facilitate choices (Salingours), promote transit (calthorbe), Continuous fabric (Lynch). In order to benefits of social and economic interaction and to increase the benefits of economic of size.

When measuring this criteria to Masr El-Gdida as traditional settlement, it has high finegrained outward oriented street network with blurring boundaries. It causes high overlap and interweave with their surroundings, with an aim to enhance relation, connectivity and continuity between city parts, they stressed the importance of being part of a city and make pressure on the public domain to enhance urban development. They encourage as primary public spaces between neighborhoods (Jacob 1961). It depends on linked structures from the very large to the very small, multilayered transportation network, sufficient fine-grained infrastructure to facilitate choices (Salingaros 2004), promote transit and more compact urban form, and mixed use and walk-able neighborhood (Calthorpe 2004), and promote continuous fabric.

On the contrary, New Cairo as new Egyptian settlement depend on neighborhood model that is self-contained internally focused unit of the city, turned inward to intend isolation and 
separation from the city and intend to keep out unwanted and use arterial roads to form borders to isolate the neighborhood residents from the surrounding urban fabric. In addition, it aims to locate services area at the center of the neighborhood and remove any use from the arterial roads. Accordingly, it neglects macro scale and public domain and restricts face-toface contact among micro community citizens. It reduces interaction and reduces alternative transportation options; modern neighborhood encourages the young families to prefer to stay in; and breaks the connection with adjacent areas, then new settlement in comparison to traditional cities have no design reference in these theories and could build week spatial fabric.

\subsection{Movement behavior (Walkability and alternative transportation options):}

It considers the role of urban form to reducing travel distances, time and cost, reduce traffic volumes and to discourage private mobility and to support, encourage and facilitate alternative modes of movement including walkability, non-motorized mobility, and public mobility as feasible solutions.

When measuring this criteria to Masr El-Gdida as traditional settlement, it is found that it built on relatively high density, mixed use, and radial grid street pattern that creates high connectivity and high proximity, it provides all services especialy daily one within walking distance and avoid longer distances and consumption of more time. also it is built as mixed use that provides secure streets full of life that encourges walkability at any time of the day. Besdie the relative high density and community size make it more feasable to provide and encourage public transportation and discourge private car deendency. It makes walkability and alternative public transportation as a viable solution than using private car. It encourages walking; enabling residents to perform daily activities without the use of a car. It also has pedestrian transportation web that built over time with continuous incremental additions without its builders being aware of it (Salingorous, 2003). Its pedestrians do not need to compete with cars.

On the contrary, New Cairo as new Egyptian settlement built on low density, separate use, and treed street network pattern that cause low connectivity and low proximity that affect movement behavior and mode choices. Beside its low density reduces community sizes and make public transportation as unfeasible solution that reduces choices of public versus private transportation. Modern neighborhood relies on single use that separate services area from the residential units. Daily needs are not met in the neighborhood, services located at large distance from residential area that make residents are forced to move long distance and high frequent trips that consume more travel time, cost and effort to reach services. Accordingly, residents have to travel by car to find services (Mark Granovetter 1983; Calthorbe ; Leyden 2003). In addition, streets lack surveillance and reduced sense of safety and security. Accordingly, walking and cycling become unacceptable solution for residents. Beside low proximity and connectivity that make residents face long distance, trips that residents need to cut for every day trip and make public transportation be unfeasible solution. It is a caroriented development, unsafe for pedistrian. With non-compactable public transportation, private car become the most feasible solution for residents, and increase their rates of car ownership. The high frequent long distance trips between residential area and services with the high rates of car ownership cause high traffic congestion especially on arterial roads and high traffic cognition at peak hours greater than traffic cognition that take place in traditional cities. With the high demand for car ownership that ranged between two to three car lots per family, accordingly it revealed shortage in parking areas.
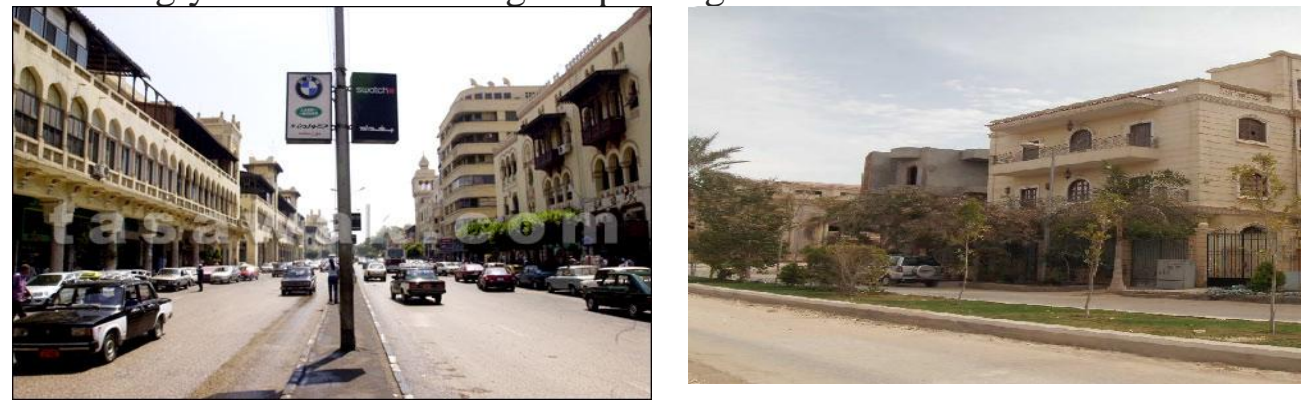
a) Masr El gdida - traditional cities

b) New cairo - modern settelments

Figure (2): comparison between traditional and new settlements Street.

\subsection{Connectivity and Permeability:}

It considers the role of urban form that makes it easy to move through an environment and depends heavily upon the paths and objects placed within the space and to connect people with each other and to facilities. (Evans 2001, Ian Bertly 1990).

When measuring this criterion to Masr El-Gdida as traditional settlement, it is found to follow fine-grained street network that implies high value of intersections, and egress points, it increases urban permeability and connectivity of spatial fabric. Accordingly, it allows many alternatives choices, which generate many alternative paths by permutation.

On the contrary, New Cairo as new Egyptian settlement follows super block model that reduce connectivity and permeability and discourage public rights to reach services amenities and urban space, street livability, pedestrian, pickles and car alternatives' and so do not support public life in the city, and limit choices of paths. It may be harmful to livability in the city as they create inaccessible areas, disconnected from the urban fabric, hence reduce the ability to access and possible benefit of services. Besides, it increase the extent to which urban forms restrict movement of people or vehicles in different directions hence it weakened the concept of permeability and connectivity, which are rarely equitable, inaccessible to public transit, and depend on automobile.

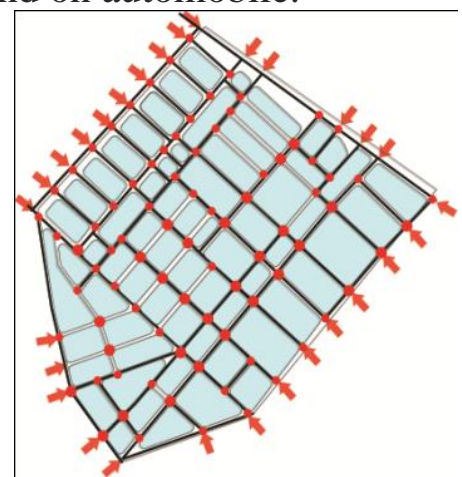

a) Masr El gdida - traditional cities

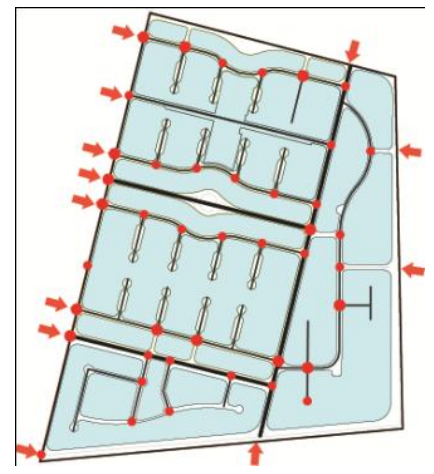

b) New cairo - modern settelments

Figure (3): comparison between traditional and new settlements connectivity.

\subsection{Encourage Public Realm to Stimulate Face-To-Face Interaction}

It considers the role of urban form to encourge the language of public participation with other diverse community levels it considers a link to vital social life to enable the city to develop social relations and promote sense of engagements, civic involvement, public responsibility and pride. Also it considers to engage citizen into the society politically and psychologically (Sennett, 76).

When measuring this criteria to Masr El-Gdida, as traditional settlement, it is found that it strive for successful streets, sidewalks and public domain to generate a common ground for residents, beside it encourges high walkability that make it increase residents chances for meeting each other, It makes their residents more connected to each other and to their community. Accordingly, they are more likely to know their neighbors, more likely to trust or have faith in them and accordingly enhance interaction between resedint intentional or accidental. It enhances interaction to share knowledge and wisdom and a flow of ideas to enrich resident's knowledge base. They can encourage a sense of trust and a sense of connection between people. To many residents, such contacts breed a sense of familiarity. They create a web of public respect and trust, and a resource in time of personal or neighborhood need (Houghton 2006; Berube 2005; Lofland, 1973).

On the contrary, New Cairo as new Egyptian settlement is single use development that promotes to separate commercial area residential one, which is depending mainly on private car, and discourage walking in the city. It donot provide common areas, accordingly it reduces the chances for meeting their neighbours and knowing them and fair to trust them and discourge interaction between resedint. No longer are public spaces shared by all urban residents as in traditional cities, which increase the distance between different social groups. 
This reflected on spatial and social pattern of development in cities to restrict it to be spaces with sole use of certain homogeneous social groups alone. New settlements discourage social interaction by extending distance between places; houses are position services far from residential building. It discourages the public space, residential interaction is supposed to take place within the home or in the backyard. It does not provide places to spontaneously encourage social interaction; rather social interaction is more likely to occur by invitation, not by chance encounter. Accordingly, they discourage sense of trust and connection between residents who lack sense of familiarity and knowing strangers (Mark Granovetter 1983; Calthorbe ; Leyden 2003). In addition, it diminishes the social role of traveling routes in the city, as part of public life which supposed to be places for diverse residents participation in social life, and hence the traveling routes, become left over's and out of the life from residents.

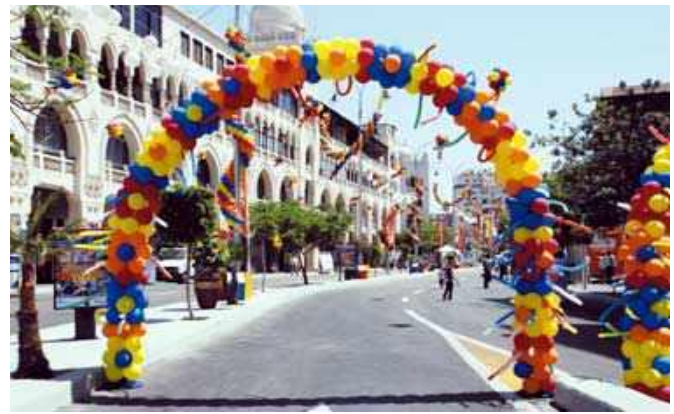

a) Masr El-Gdida - traditional cities

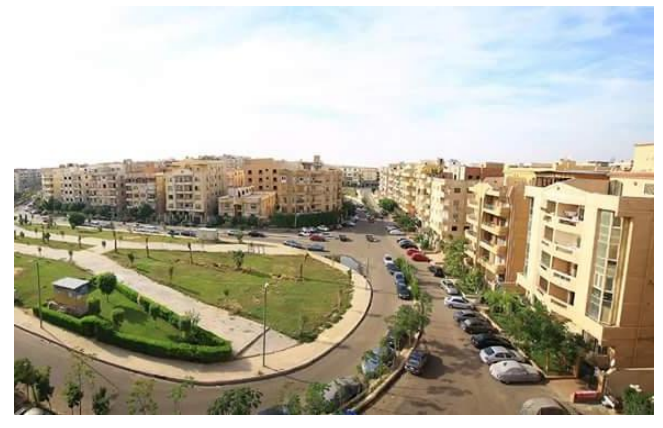

b) New cairo - modern settelments

Figure (4): comparing the welcoming role of public spaces.

\subsection{Safety and Security:}

It considers the role of urban form to provide sense of safety and security for their residents and to self-reduce crime opportunities, without using reinforcement methods and physical instruments, and the role to increase surveillance, and territoriality.

When measuring this criteria to Masr El-Gdida as traditional settlement, it is found that it is mixed community that encourage walkability and public realm that attracts people continuous movement during day and night. In addition, it has sufficient dense concentration of people that avoid empty spaces, make spaces full of people. Accordingly, it ensures a relatively high degree of continuous natural surveillance, that provides residents with sense of safety and security (Bahamam 2001; Camona 1997). Beside the high relationship exist between their residents make them define strangers and define criminals and accordingly reduce crime rates. On the contrary, New Cairo as new Egyptian settlement reduces community size, split service area from residential street, accordingly reduces through movement of people and cannot animate streets, it loses life, streets is empty, it lakes natural surveillance and supervision all day and night, it lacks safety and cause high crime rates. In addition, it reduces relationship between residents and reduces trust and faith in them, that makes resident hardly know each other and hardly recognize strangers and offenders.

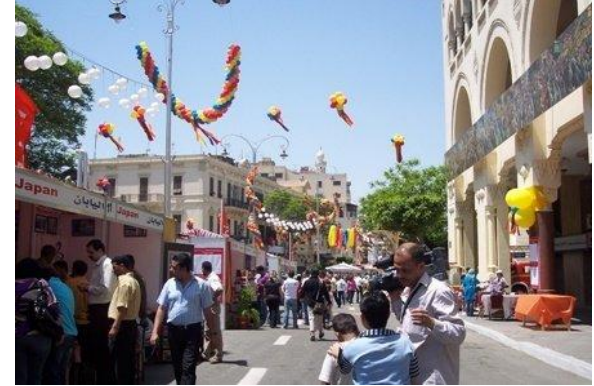

a) Masr El gdida - traditional cities

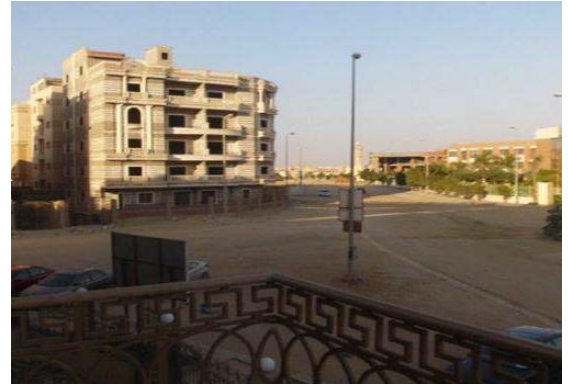

b) New cairo - modern settelments

Figure (5): comparing the security role of public spaces. 


\subsection{Diversty and Mixed Community}

It considers the role of urban form to promote integrated mixed socio-economic diversity environments to diverse housing types, the amount and the kind of human activities, i.e. walking, sitting, doing commercial exchanges, making pictures on a sidewalk, talking that are shared between them.

When measuring this criteria to Masr El-Gdida as traditional settlement, it strive for mixed communities that encourage diversity of incomes, tenures, housing and socioeconomic levels, this give the chance of having diversity of building types, heights, shapes, functions, and uses. In addition, it gives diversity of people who are using urban spaces and accordingly a diversity of activities and mode choices. This also gives residents the chance to interact with other social groups and exchange their experiences with other different. In addition, it could become an effective place for socializing future generation, and for exchange and contact of knowledge, experiences, and information with other diverse social groups, which could perpetuate trust and unity. It provides diversity and variety of commercial activities, opportunities, inhabitants, visitors, tastes, abilities, and needs. (Jacobs, 1961).

On the contrary, New Cairo as new Egyptian settlement strives to center the plans on single housing income groups and to spelt-diversified residents and keep homogeneity. This could limit social interaction inside the community to a restricted social group and exclude the others, and neglect public life. Accordingly, it affects types and density of human networks and reduces interaction. It also limits the provided opportunities, choices and chances to very strict limits. In addition, it limits building types, height, shapes, form, function and uses to strict types. It reduces diversity and variation in urban, visual and social relations.

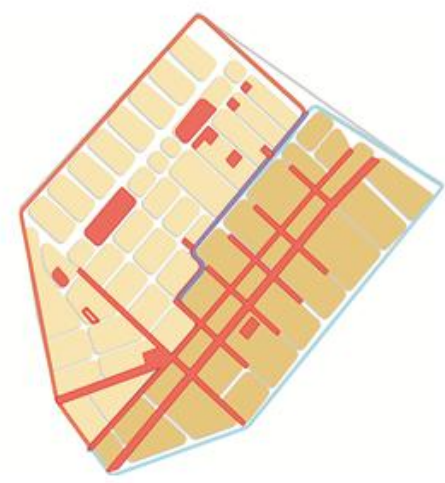

a) Masr El gdida - traditional cities

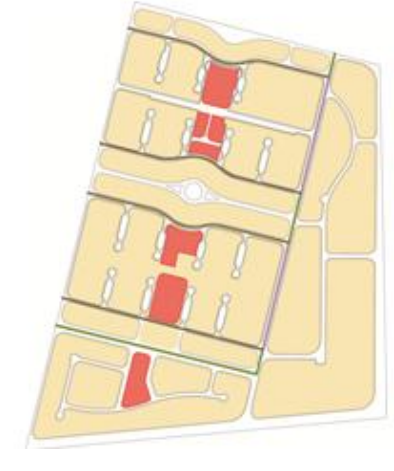

b) New cairo - modern settelments

Figure (6): comparing land-use pattern.

To summarize, new-settlements in comparison to traditional cities, do not provide the required diversity, and variation required in urban and architecture forms, and lake social relations between residents of diverse social groups, and lake alternatives forms for movement behavior and transportation options. New settlements stand short when measured to these criteria.

\subsection{Social Appropriatness:}

It considers the appropriateness of new development patterns to socio-cultural fabric of Egyptian society that implies religion, culture aspects, social aspect, and Egyptian people preferences. Traditions, religions advice that the peace and stability of society depend on good social relations among the members of society. Especially, the relation between the rich and the poor. Egyptian people often prefer streets, buildings, neighborhood, and even the city, is filled of life and activities, stressing concepts of „ulfa“, „lama“, „wanass“(Ghannam 2002, Abd El khalek 2009). They like neighborhoods to be abundant with life and activities, thus be safe. They prefer familiarity and intimacy created through the gradual rootedness in a specific place over a long period based on gaining knowledge of others, place each other, know each other, and being able to place them. They prefer to feel satisfaction that comes through gathering people into one place. It indicates the mixture of different population that brings good and bad together (Abdel khalek 2009). 
When measuring this criterion to Masr El-Gdida as traditional settlement, it relies on compact mixed-use urban form, buildings and services in walking distance that reduce travel distance and become welcoming for walkability. Accordingly, it increases resident's chances for meeting each other in services area and while they are walking. They are more likely to know each other, they are more likely to trust or have faith in each other and enhance the trust and reciprocity between each other, they are more connected to their community, and it provides local sense of community and identity. In addition, it relies on mixed housing income that encourages the relation between the rich and the poor. It also encourages public domain with commercial axis that make streets abundant with life and encourage public spaces the place of resident's interaction that encourage some kind of contraction, involvement and participation in micro community.

On the contrary, New Cairo as new Egyptian settlement depends on homogeneous community that lack diversity, and strive for exclusion of the poor. It is spatially segregated that divide and cut the continuity between neighbors society residents. It tends to diminish public realm, leading to dividing urban form by main arterial roads with no use, and with no public urban spaces, which week concepts of "Ulfa", "Lama", "Wanass" that are socially rooted in Traditional Egyptian social fabric. That makes streets quit, empty, not inhabited or used by people thus scary and unsafe areas, just like streets at night. This negatively affects the liveability of the city; isolating public streets from its life, and converting it to merely some zones that motor paths have penetrated it.

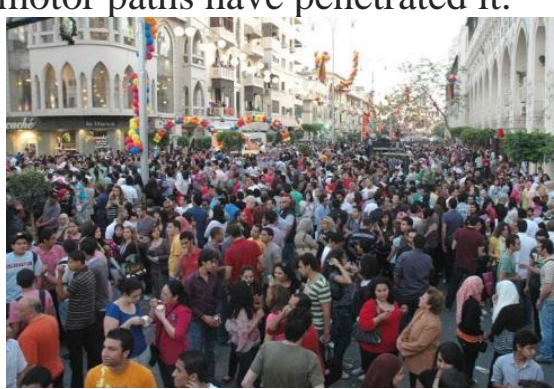

a) Masr El gdida - traditional cities

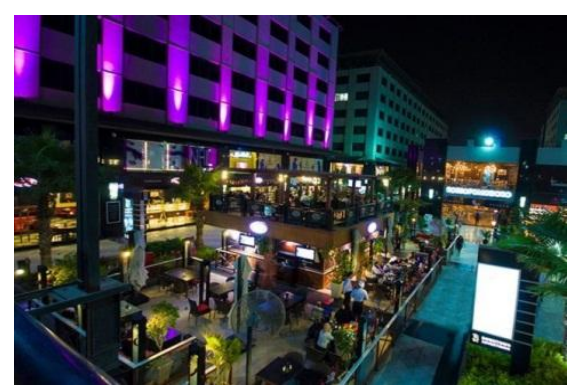

b) New cairo - modern settelments

Figure (7): comparing Social appropriateness and equality.

\subsection{Efficient Use of Resources}

It considers the economic aspects of using environment resources. An environmentally economic sustainable settlements, is the one that create context compatible physical design that can reduce energy consumption to fit climate impact on architecture hence reduce using air conditioning, and encourage residents to reduce relying on private cars and depend on alternative modes including walking, cycling, and public modes of transportation. Such modes reduce energy consumption and can reduce traveling distance, fuel consumption, and travel cost.

When measuring this criterion to Masr El-Gdida as traditional settlement, it depends on compact form to generate short distance trips. Where residents found all services within walking distance, and found a welcoming urban form that, encourage pedestrian movement. Accordingly, it reduces motorized movement, reduces communizing cost, and makes residents rely on modes of travel that reduces energy consumption and achieve equitability and affordability. They strive for compact development, that can reduce climate impact on urban form hence reduce using air conditioning. Beside most services are located within walking distance, it encourges public transportation, walkability and discourge private car, accordingly it reduces travel distance, fuel consumption, and commuting cost. In addition, it relies on using restricted area of land to save land.

On the contrary, New Cairo as new Egyptian settlement strives for sprawled development and homes are often located at great distances from services that discourage walking and increases dependency on the private car and causes excessive commute times and cost, traffic congestion, high communizing cost and inefficient energy consumption. In addition, it relies on sprawled low-density very large distance between building that reduces building densities and increase land consumption. On the contrary, New Egyptian settlements causes long distance trips that make residents rely on private car, accordingly consume high-energy rates, 
excessive commute times, traffic congestion, inefficient energy consumption, and loss of open spaces. Besides, it fails to reinforce street as public spaces that encourage pedestrian and biking travel to bring people together, which could facilitate an economic arrangement, encourage street activity to support retail businesses. It is inefficient in losing opportunities of exchange, public life and streets activities.

\subsection{Equitable Management of Resources}

It considers the social aspects of using environment resources. An environmentally economic sustainable settlements the one that comes through equitability in economic growth regarding resources distributions, citizen participation, access to services, and concern for all members of the community.

When measuring this criterion to Masr El-Gdida, as traditional settlement, it concerns how to confirm equity for citizen participation, equal access to services, concern for all members of the community, and interested in equitable economic growth that not only concern for growth rather the equitability of income distribution in land use. Besides, it concerns how to reinforce street as public spaces that encourage pedestrian and biking travel to bring people together, which could facilitate a more economical of arrangement, encourage street activity to support retail businesses.

On the contrary, New Cairo as new Egyptian settlement strives for inequity, refer to the disparities and fairness of distribution, that individuals and groups require differing levels of support in order to flourish, and that some individual and groups can contribute more than others can. New communities limit levels of involvement and impede optimal healthy development of individuals and groups and the community as a whole. New settlements are inequitable and inefficiently in its distribution of economic resources, and job housing imbalance. Besides, it is inefficient in its impact on loss of opportunities of exchange, public life and streets activities.

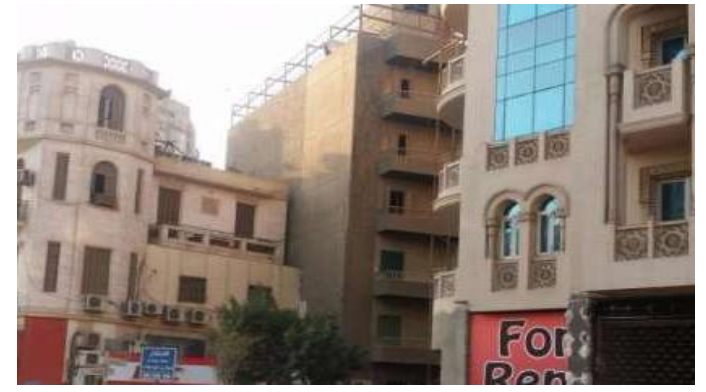

a) Masr El gdida - traditional cities

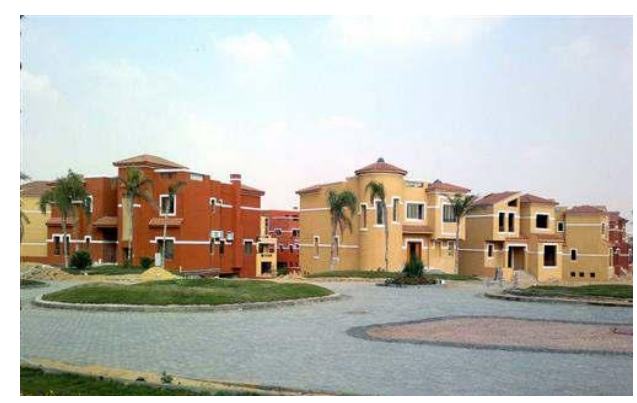

b) New cairo - modern settelments

\subsection{Consideration of Environmental Impacts.}

It considers the climatic design in hot arid zones to reduce uncomfortable environmental conditions created by extremes heat and dryness, reduce resources consumption, (water and fuel). GCR new towns have been developed in the eastern and western desert as an arid region that has its special features which characterize its climate and soil form, where a high mean duration of sunshine, minimal rainfall, high level of solar radiation, excessively high temperature, water scarcity and deficiency of suitable land for agriculture (El-Zamly 1994).

When measuring this criterion to Masr El-Gdida as traditional settlement, it depends on short distance buildings and services that are in walking distance. It is pedestrian oriented, that reduce car dependency and accordingly reduce environmental and noise pollution caused by high frequent trips and reduce resources consumption. It is developed in high density that increases the feasibility of public transportation. In addition, it relies on compact form with short distance buildings and services are in walking distance; this reduces resource consumption and environment pollution. It aims to plan urban fabric with narrow streets, using compact urban form and in close proximity of urban services and daily functions within walking distance. Accordingly it provides maximum shade to protect from solar radiation, allow minimum reflection in streets and open spaces and minimize indirect solar radiation to avoid heating the air, (Golany 1978), and to provide relatively cool and break stormy winds, but allow through-ventilation and adequate natural lighting. Finally, it includes green areas of 
plants around and within the settlement to provide shade and cool air with limiting green area so to reduce water consumption.

On the contrary, New Cairo as new Egyptian settlement is developed on sprawled large areas of lands with low densities, with separated large distanced buildings, segregated separated services, and not on walking distance, so commuting depends mainly on private cars that create longer commuter journeys, increase car trips and traffic cognition during much of the day. Accordingly increase co2 emission, air pollution, increase fuel and energy consumption. A huge daily and weekly trips are generated, especially with the high rate of car ownership when each family owns more than two cars. It is predictable in the future to consume a high increase in energy and resources consumption that affects the environmental sustainability. Therefore, it is not considering the climatic condition of Egypt deserts, regardless of the environmental concerns that have been recommended for arid regions (Kuppinger 2004). It increases environmental negative impacts since it increase car trips with long distance trips, accordingly increase resource consumption and increase (air, noise,) environmental pollution. They are in low density with large sprawled areas of lands, with separated large distanced buildings, separated services, and not on walking distance, so commuting depends mainly on private cars and consume more frequent long distances trips that consume more commute time and fuel. In addition, large open spaces with no shaded spaces mostly include large green areas, which increase more water consumption. Also modern neighborhood in macro scale create sprawled and separated large distances areas between micro communities inside the overall city fabric, which consume more time and resources in commuting.

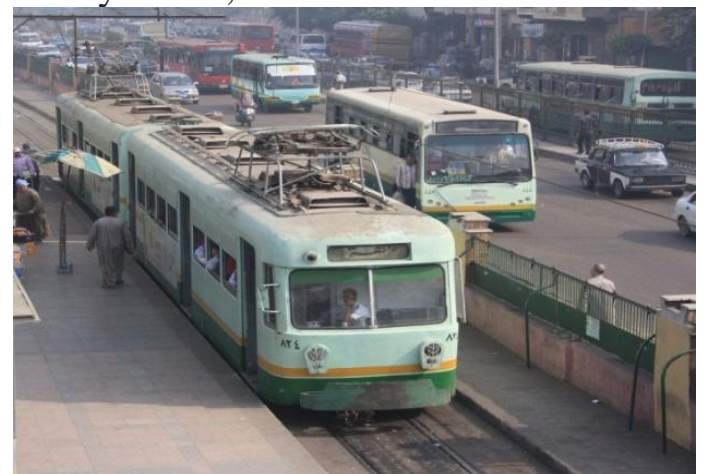

a) Masr El-Gdida - traditional cities

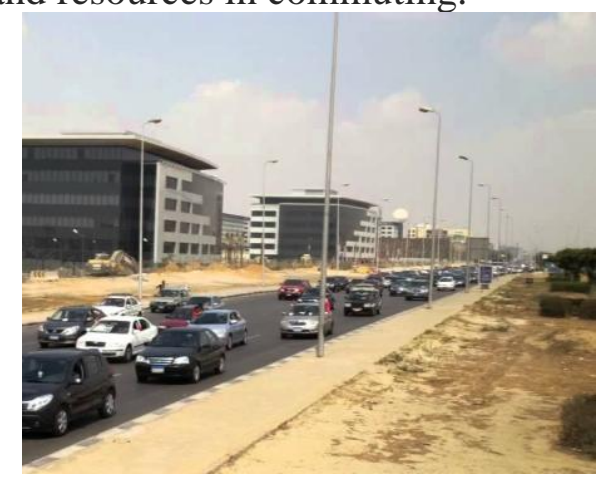

b) New Cairo - modern settelments

Figure (9): comparing resources consumption due to long distance high trip rates based on private to public transportation.

To summarize, modern neighborhood compared to traditional one did not solve the problems of old towns rather it becomes part of the problem of new settlements. When measuring the deduced shared premises to new settlements we found it stand short to achieve them:

It did not provide people with alternative varying transportation options, it discourages the public realm, walkability, and it increases reliance on private car with increasing private car trips and their distances and increase cognition. Beside it cause a shortage in parking areas, high frequent long distance trips, high traffic cognition at main streets, and high traffic cognition at peak hours greater than traffic cognition that take place in old traditional cairo. In addition, it did not provide sufficient interaction between residents, safety and security, and probably increase crime rates. It is not efficient in using resources, and not equitable in distribution of it. In addition, it does not consider the negative impacts on the environment and do not save their resources. Finally, it consumes high economic cost for communizing.

It is concluded that new settlements stand short when measured to the AIA's principles for livable communities, UN principles for sustainable communities, new urbanism principles for smart growth. New settlements compared to traditional one is not sustainable, livable, and not healthy community.

\section{CONCLUSION}

This paper introduces some evaluation indicators to facilitate the examination of the sustainability of new settlements in Greater Cairo Region. These indicators are derived from 
two evaluation references, the first classic and modern movements of urban form; and the second from unique environmental, social, and economic circumstances of GCR.

The paper reveals that New Egyptian settlements have no design reference in modern movements and theories of successful spatial fabric, social fabric, and city public life. In addition, the research revealed that New Egyptian settlements are not suitable for development in a unique context like Egypt; they are not compatible with environmental, social, and economic context. New community's socio-spatial features have a deep impact on spatial and social fabric of our cities; accordingly, they have deep negative impacts on urban development.

Traditional settlement appeared to reflect good urban form theories in their aim to achieve sustainability, livability, healthy community, as a way for curing the contemporary problems of sense of identity and community. There is a need for revision of using modern patterns, and a need for design regulation tools to control their growth. Municipality should put strict urban legislation that takes in consideration the impacts of modern neighborhood on the achieved development.

The research recommends a return to traditional mixed-use, high density, and fine-grained outward oriented and integrated with the city with high connectivity and permeability to get lessons to build new communities. It is required to build new communities based on a deep awareness of the impact that new patterns could impose on urban development, in reference to Egypt environmental, social and economic unique circumstances. On the other hand, the built and occupied new Egyptian cities need to consider partially or fully a process of intensification by increasing density, force mixed use and encourage connectivity and permeability of urban fabric. There is a need for toolkit repair tool to enhance movement behavior, based on pedestrian encouragement, public transportation feasibility, to encourage resident's interaction and to reduce negative impacts on the environment and reduce resources consumption.

\section{REFERENCES}

1. (Leed-ND) () "A Citizen's Guide to LEED for Neighborhood Development: How to Tell if Development is Smart and Green", united states green building consul.

2. Alexander E (1993) Density measures: A review and analysis. Journal of Architectural and Planning Research 10(3): 181-202.

3. Alexander, C. (1965) "A City Is Not A Tree", Architectural Forum, Vol 122, No 1, April 1965 , pp 58-62.

4. Baldassare M (1982) The effects of neighborhood density and social control on resident satisfaction. Sociological Quarterly 23(1).

5. Bayoumi, W.N.A. (2009) The Tale of the Unsettled New Cairo City-Egypt: A Review for the Implications of the Adopted Privatization and Laissez- Fair Policies on Excluding the Poor from its Housing Market, Young Academics Network Vienna.

6. Berman MA (1996) The transportation effects of neo-traditional development. Journal of Planning Literature 10(4): 347-363.

7. Berube, A. (2005) "Mixed communities in England: A US perspective on evidence and policy prospects" Joseph Rowntree Foundation.

8. Blandy, S., Lister, D., Atkinson, R. and Flint, J. (2004) Gated communities in England Final report of the Gated Communities in England 'New Horizons' Project.

9. Bramley G, Power S (2009) Urban form and social sustainability: The role of density and housing type. Environmental Planning B 36(1): 30-48.

10. Breheny M (1992) Sustainable Development and Urban Form, London, UK: Pion.

11. Bridger JC, Luloff AE (2001) Building the sustainable community: is social capital the answer? Sociological Inquiry 71(4): 458-472.

12. Burgess R (2000) The compact city debate: A global perspective. In: Jenks M, Burgess R (eds) Compact Cities: Sustainable Urban Forms for Developing Countries, London, UK: EFN Spon, pp. 9-24.

13. Calthorpe, P. (1993) "The Next American Metropolis": Ecology, community and the American dream. Princeton Architectural Press: New York, USA.

14. Calthorpe, P. (2003), "The Regional City", time saver - standards - for urban design. 
15. El-Zamly, H.A. (1994) Arid Zones: A New Trend in Planning Education, Cairo University Cairo-Egypt.

16. El-Zamly, H.A. (1999) Arid Zones: A New Trend in Planning Education, 2nd International Symposium, Planning Education in the 21st Century: Past Experiences and Future Responses Faculty of Urban and Regional Planning- Cairo University Cairo-Egypt.

17. Ghonimi I., Alzamly H., Khairy M. and Soliman M., 2010, "Against the great divide between theory and practice: Gated Communities versus urban livability", Corp.

18. Ghonimi I., Alzamly H., Khairy M. and Soliman M., 2010, "Understanding and formulating gated communities inside Greater Cairo new towns urban fabric", 46th ISOCARP Congress, 19-23 September 2010, Nairobi, Kenya.

19. Jacobs, J. (1961), The Death and Life of Great American Cities, New York: Vintage Books, 1961.

20. Kuppinger, P. \& College, M. (2004) 'Exclusive Greenery: new gated communities in Cairo', City \& Society, vol. 16, no. 2, pp. 35-62.

21. Landman, K. (2004) "Gated communities in South Africa: Comparison of four case studies in

22. Leyden K (2003) Social capital and the built environment: The importance of walkable neighborhoods. American Journal of Public Health 93(9): 1546-1551.

23. Lynch, Kevin. 1981. A theory of good city form. Cambridge: MIT Press.

24. Minette, J. (1975) "As the City is not a Tree... it should not be designed as a System", planning outlook new series, volume sixteen.

25. Salingarous (2003) "Connecting the Fractal City" In: 5th Biennial of towns and town planners in Europe, Barcelona, Spain.

26. Sennett, R. (1976), " The fall of public man", Cambridge: Cambridge University Press, 1977.

27. Shalaby, a, F (2003). Transfer of Ideas through Planning Education in Egypt: The Case of the Spatial Form of Low Income Housing Cardiff University, Cardiff.

28. Yang Y (2008) The tale of two cities: Physical form and neighborhood satisfaction in metropolitan Portland and Charlotte. Journal of the American Planning Association 74(3): 307-323. 